Volume 3

Number 3 Virtual Platforms: Spaces of Control

Article 9 and Contestation

2018

\title{
Searching: On the Cultural and Sociopolitical Implication of Social Media
}

Siamak Javadi

University of Texas Rio Grande Valley

Follow this and additional works at: https://digitalcommons.uri.edu/mgdr

Part of the Economics Commons, Marketing Commons, Other Business Commons, Political Theory Commons, and the Sociology Commons

\section{Recommended Citation}

Javadi, Siamak (2018) "Searching: On the Cultural and Sociopolitical Implication of Social Media," Markets, Globalization \& Development Review: Vol. 3: No. 3, Article 9.

DOI: 10.23860/MGDR-2018-03-03-09

Available at: https://digitalcommons.uri.edu/mgdr/vol3/iss3/9

This Media Review is brought to you for free and open access by DigitalCommons@URI. It has been accepted for inclusion in Markets, Globalization \& Development Review by an authorized editor of DigitalCommons@URI. For more information, please contact digitalcommons-group@uri.edu. 
Searching: On the Cultural and Sociopolitical Implication of Social Media

\section{Cover Page Footnote}

Special thanks to Deniz Atik and Aras Ozgun for helpful comments and suggestions.

\section{Markets, Globalization \& Development Review}
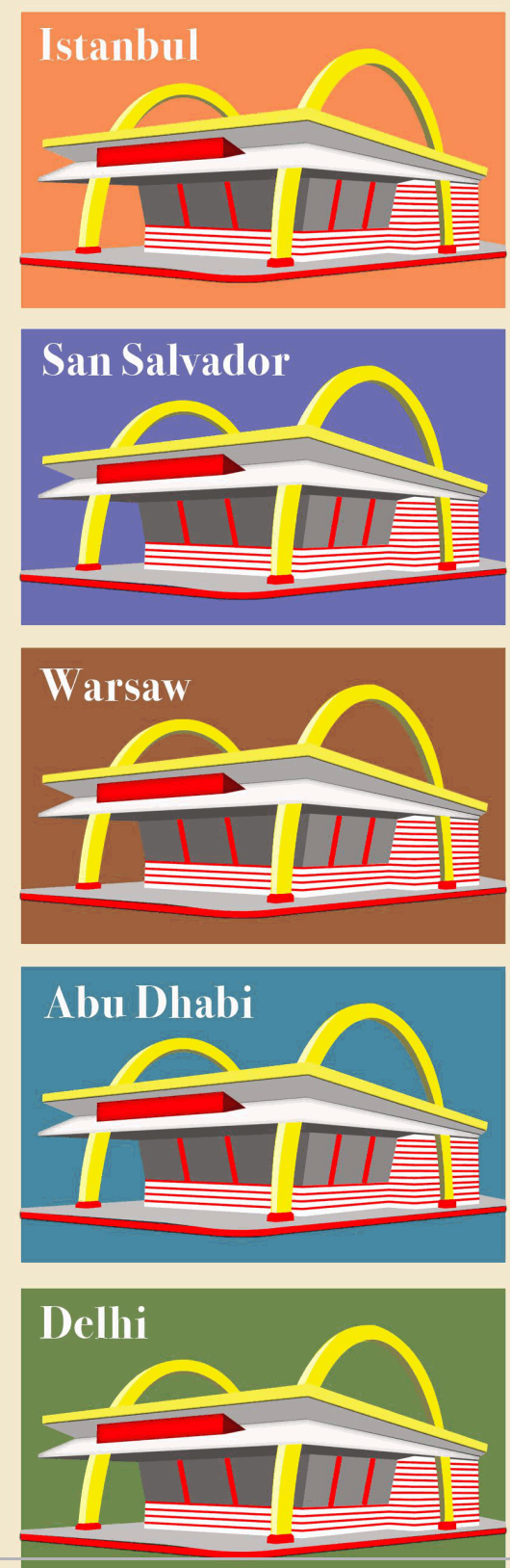

This media review is available in Markets, Globalization \& Development
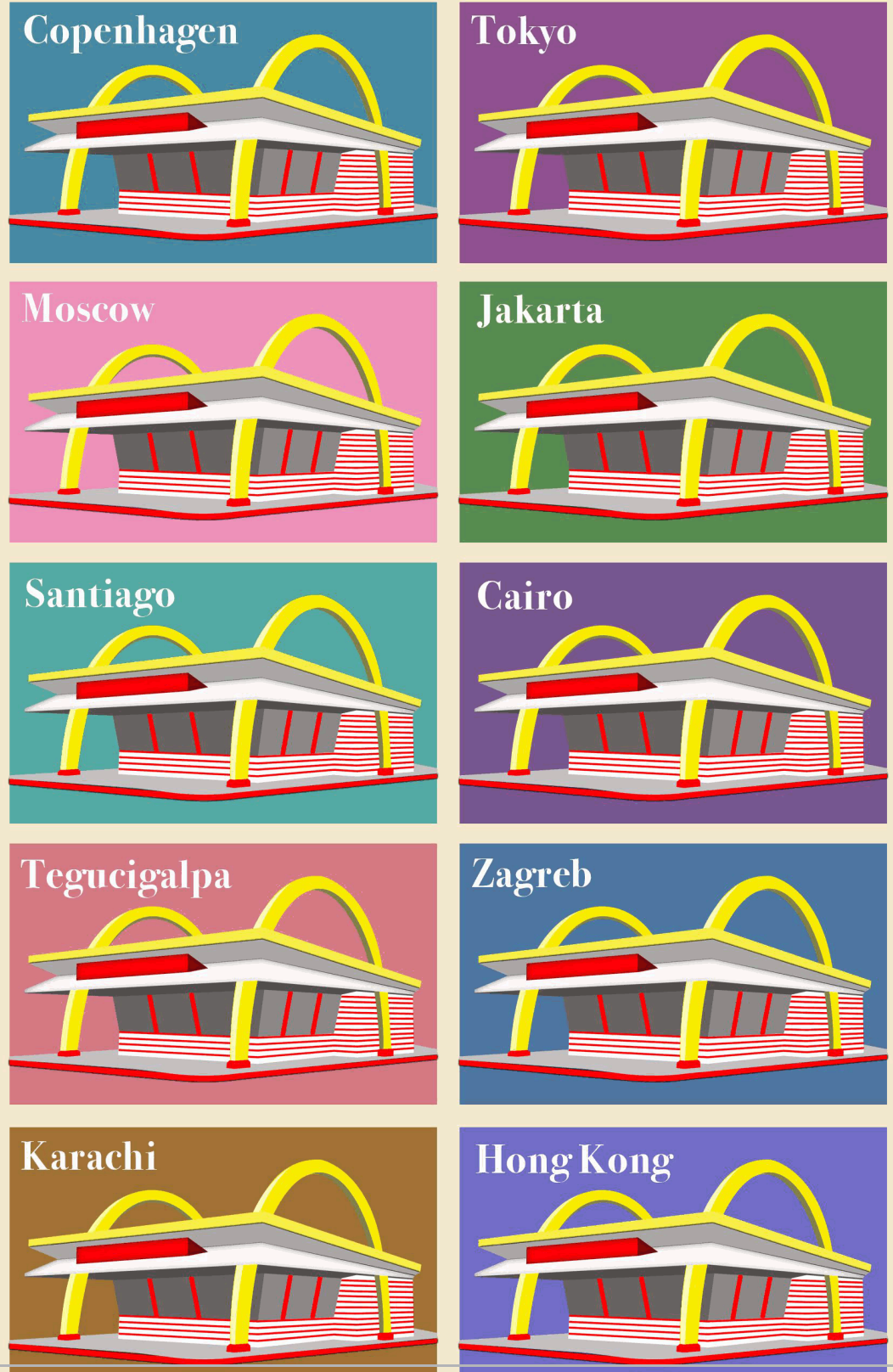

mgdr/vol3/is 


\section{Film Review}

\section{Searching: On the Cultural and Sociopolitical Implication of Social Media}

\section{Overview}

Searching (2018) is a multilayered thriller co-written and directed by Aneesh Chaganty in his debut feature. Chaganty has managed to transform a typical missing-person thriller into a cinematic reflection of the profound impact that social media networks have had on every aspect of our lives, while telling a very engaging story. Throughout the film, Chaganty continuously and masterfully navigates between the pros and cons of social media platforms and explores a series of pressing questions in the age of social media networks: If and to what extent does our online identity differ from our offline identity? How much do we really know the people close to us and do social media networks have something to offer? Does the easy access to information that comes with these platforms empower the public and promote a sense of self-responsibility? Would these platforms create freer societies with better- and more-informed citizens, or to the contrary, are they a tool for thought control and indoctrination of societies? Is the rise of social media platforms widening the range of acceptable views or are these platforms just allowing for a lively debate within even narrower limits? In this review, I focus on these questions in relation to the film.

\section{Background}

The plot happens in San Jose, California, and centers around a tech savvy widower, David Kim (John Cho), whose 16-year-old daughter, Margot (Michelle La), goes missing one day. Distraught and desperate to find Margot's whereabouts, he goes through her social media with a fine-tooth comb and follows her digital footprint looking for clues while sharing that information with Rosemary Vick (Debra Messing), a police detective, who is investigating the case. After a series of twists in the plot, a former convict, Randy Cartoff (Ric Sarabia) confesses in an online video to sexually assaulting and killing Margot. He kills himself afterwards by a self-inflicted gunshot wound, and essentially puts an end to the investigation. However, in an unexpected turn of events, David learns that contrary to what detective Vick had claimed about being assigned to the case, she had, in fact, volunteered to take it. With a quick Google search, David finds out that detective Vick and Cartoff knew each other. With this revelation, the detective is later arrested and confesses that throughout the entire 
investigation she misled, obstructed the truth and forged fake documents to cover up an incident that involved her son accidently pushing Margot off a 50-foot ravine. Eventually, thanks to a storm that happened a few days prior to Vick's arrest for providing water for Margot's survival, she was found alive and reunited with her father.

\section{Social Media Platforms: The Cultural Implication}

The opening scene is very telling and sets the tone for the rest of the movie. Chaganty begins the film with a shot from a computer screen showing the desktop page of Windows XP. One of the crucial and creative dimensions of Searching is that the entire film transpires on a computer or a cellphone screen. It reflects the ever-vanishing line that separates the virtual life from the physical life. This form of narration particularly strikes a chord as we spend a growing percentage of our waking hours staring at screens (Nielsen Company Report 2018; NBC News 2018). It also demonstrates the gradual integration of the offline "real" life and the online virtual "life" and casts doubt on the conventional view about what is real and what is not.

Moreover, the film shows the progression and evolution of virtual platforms, and how they have been finding their ways into our lives. The brilliance of Chaganty is that, within the first five minutes of the movie, while he is providing context to the characters and telling the history of the Kim's family, we see the rise and emergence of companies, technologies, and virtual media platforms that have completely transformed our lives and the way the world operates. It begins with Windows XP and Internet Explorer, and then continues with YouTube, Skype, Facebook, and Google Chrome. Very much like a religion that is present in one's major life events, we observe the constant presence of these technologies and platforms in Margot's major life events: first day of kindergarten, first piano lesson, first day of $1^{\text {st }}$ grade, first day of $4^{\text {th }}$ grade and so no. The scene where the question "how to fight lymphoma as a family" is searched on Google (3:24) solidifies the significant status of these platforms and the extent to which they are woven into our lives.

One of the defining characteristics of our era is our complete dependence on social media platforms and related technologies for our daily activities. This is also a common recurring theme in the movie and its main premise; from the innocuous Google search for "electronic store near me" and looking up the contact information of Mrs. Shahinian, the piano teacher, in Gmail to more consequential searches such as those related to Cartoff, detective Vick, and fish_n_chips' profile-picture. Chaganty harnesses this phenomenon to his advantage and throughout the movie, he consistently portrays the pros and cons associated with social media 
platforms. After Margot goes missing, David realizes he does not really know much about his daughter. He hacks into her social media and tracks down her digital footprint to get some insight about who she really is. The main thrust of Searching, that our interaction with social media sheds light on our identity, is the manifestation of the reality of our world today and reinforces the idea that our digital avatar is perhaps as real as our physical self and provides a rich insight about our deepest thoughts and motives. This is consistent with the emphasis of law enforcement agencies, specifically in the US and more generally around the world, to monitor and scrutinize social media activities of people of interest. When during her confession, detective Vick says that Margot was "a good kid" (1:28:46), she does not mean that in a rhetorical sense. Margot is in fact a good kid because we see her true motives. Quitting her piano lessons and transferring the funds to herself and eventually to fish_n_chips did not have any sinister reason. Empathizing with her "online" friend whose mother is fighting cancer, she wanted to help her with hospital bills. This is an example where we are presented with convincing evidence about Margot's true character and integrity through her interaction with the dark corners of social media platforms which is not readily observable in the daylight of the corporeal life.

Like any other new technology, social media platforms and their related technologies have their own downsides. These platforms are prone to hate speech, conspiracy theories and misinformation and can distort the perception of reality. In the movie, haters start their own campaign. We see \#FindMargot goes viral, but so does \#DadDidlt. These drawbacks of social media platforms were not unknown but they have grabbed the public's attention and triggered a global debate more recently, especially against the backdrop of the 2016 US presidential election and Russia misinformation campaign to influence the outcome of the election. How does one go about providing a platform for free expression of ideas without giving oxygen to conspiracy theories and hate speech? The answer is not clear. In the case of Alex Jones, Apple, Facebook and YouTube banned his Infowars website (see for example NPR 2018). However, this raises a series of other questions: How is banning certain views by social media platforms consistent with freedom of speech? How is it different from censorship? In fact, as pointed out by Noam Chomsky "If we do not believe in freedom of expression for people we despise, we do not believe in it at all". While the film does touch on this subject, it does not get any deeper. In my view, given the seriousness and relevance of this issue in today's world, Chaganty could have added another layer of complexity to his debut feature by exploring this issue a bit further in the plot. 
The movie also shows the crucial distinction between "real" friends, "offline" friends, and "online" friends. One may have many Facebook friends, may know many people in the corporeal social life but utterly alone. Apparently, Margo had no real friends. She has a reasonable number of Facebook friends, but to David's frustration, none of them is friends with her (31:23). She was "occasionally invited to things"; "she was quiet"; "she ate lunch alone everyday". Peter (Joseph Lee), her uncle, is perhaps closest to what can be characterized as a real friend. David begins to uncover this reality when he asks one of Margot's classmates "she has friends, right? (30:51)". The movie then immediately poses the crucial issue: "define friend". Chaganty brilliantly shows the paradoxical nature of this issue that exists within social media platforms. On the one hand, there is a group of Margot's classmates who have known her in corporeal social life and are also friends with her on social media platforms, but their relationships with her do not exhibit the features of a true friendship. In fact, they tried to have instant fame by posting on their social media, pretending to be her besties after her case became famous, while they had clearly stated earlier that they were neither friends nor close to her. On the other hand, we have the relationship between Margot and fish_n_chips. While the relation never goes beyond a social media platform, it exhibits more characteristics of a true friendship. Margot makes a sacrifice to help a friend with hospital bill. In return, fish_n_chips also has the integrity and the will to have the unpleasant conversation with Margot and return the money that he had received for hospital expenses that did not exist. Social media has provided a platform for two people who struggle in their corporeal social life to connect at a meaningful and substantive level, whereas the same platform was used by others to have instant fame or distribute misinformation.

\section{Social Media Platforms: The Sociopolitical Implication}

The plot of the film is very much consistent with capitalism. The issues of individual liberty, maximizing personal interests and limiting government interventions are at the heart of capitalism. The symbolism of the movie consistently promotes the notion of self-responsibility and individual liberty while simultaneously illustrating the inefficiencies associated with government involvement. The two pillars of Adam Smith's capitalist world (The Wealth of Nations 1776) are the maximization of personal gains and the rejection of government meddling, and the main narrative of the movie is consistent with these two pillars.

It is commonly believed that better, more accurate, and easy access to information reduces opacity of institutions, increases transparency in the society and thereby reduces the overall asymmetric information and 
therefore, economic agents would be more informed and empowered to make better choices for maximizing their personal gains. This is a crucial aspect of the social media platforms, which Chaganty explores in Searching. We see that easy access to information brought about by virtual platforms empowers David and leads to a sense of self-responsibility in him that would have not been possible without these platforms. The ubiquity of information accessibility has reached a level that is no longer obvious; it is implicit. We almost take it for granted and do not even notice the amount and the precision of the information that David continuously accesses. He tenaciously follows every lead and the digital footprint of Margot to determine her fate. He questions everything and takes an active role in the case. Even the seemingly convincing video confession of Cartoff "still doesn't make sense" to him (1:15:04). He still has many unanswered questions that Cartoff confession is unable to explain. The doubt and skepticism that David exhibits are the consequence of the transparency and the easy access to information that virtual platforms provide. In fact, this is the fundamental reason for unraveling of detective Vick's cover-up, which eventually saves Margot's life. It is clear that without these platforms, David would have not been empowered to pursue the case, detective Vick's coverup would have prevailed, and Margot's fate would have been completely different, and perhaps a tragic one.

\section{Propaganda Model}

Searching can also be analyzed within the propaganda model of Herman and Chomsky (1988). The framework explains how thought control in democratic societies works. In democratic societies, where the ruler has lost the bludgeon and people voices are and can be heard and resorting to violence is no longer an option, propaganda model suggests turning to thought control and indoctrination. In this model, agenda-setting corporate media is the essential tool for indoctrination of the societies to manufacture public consent for economic, social, and political policies that are inherently undemocratic. This is mainly done by propaganda and asymmetric coverage of the news. At the heart of this framework is the issue of what is newsworthy and what is not -the 'agenda setting' function of the news. In other words, news and events that can help manufacture the public consent to advance the favored policies are covered substantially and disproportionally more than comparable news and events that show otherwise or provide evidence to the contrary.

In Searching, David symbolizes a public that is constantly subjected to thought control and propaganda by someone in a position of power and influence. Detective Vick symbolizes the sector of the society with power and influence that wants to push the agenda that serves its interests and 
needs the public to be passive and obedient. What role can virtual platforms play in this context? As Chaganty shows us, given the easy access to information and audience that are associated with these platforms, they can provide a playground for both parties and each party can use it to its advantage. On the one hand, Vick uses the features of these platforms to deceit, give false information, and divert attention from important questions. On the other hand, these platforms and the associated transparency and information availability helped David fight the propaganda. Throughout the movie, we see the tug of war and the constant battle between these two parties. As Chomsky (1998) points out, "The smart way to keep people passive and obedient is to strictly limit the spectrum of acceptable opinion, but allow very lively debate within that spectrum ..., while all the time the presuppositions of the system are being reinforced by the limits put on the range of the debate." This is exactly the dynamic between David and Vick in the movie. Detective Vick sets the limits and allows for discussions and speculations within them, while she knows perfectly well that as long as the discussions are within those limits that she has set, the discussions are going to advance her interest. First, she initially suggests that Margot might have run away based on the fake ID that Vick herself had forged and on the $\$ 2,500$ that Margot had withdrew from her account. She then continuously attempts to condition the discussion on the assumption that she has in fact run away (47:19). David begins to resist this presupposition in the very next scene. He pushes back against the limits and widens the range of the discussion. Using the information in the social media platform and Google Map, he makes a breakthrough in the case by finding Margot's car in the lake. Next, Vick gets a false confession from an ex-convict and then focuses the discussion on that. Using social media platforms, David is once again able to overcome this presupposition as well.

A thriving democracy requires free access of information, ideas and opinions. By providing an outlet for easy access to information and to consumers of information, virtual media platforms can either be a weapon against propaganda or a tool to facilitate it; they can either broaden or limit public debate and deliberation depending on the quality of the information. Chaganty has a positive outlook on this issue. He ends the film on a positive note, implying that in this constant battle between the benefits and the dangers of these virtual platforms, the positive effects are victorious. 


\section{References}

Chomsky, Noam, David Barsamian and Arthur Naiman (1998), The common good. Monroe, ME: Odonian Press.

Herman, Edward S. and Noam Chomsky (1988), Manufacturing consent: The political economy of the mass media. New York: Pantheon Books.

Realistic screen time solutions for kids (and their parents), NBC News, Feb.22, 2018 (accessed December 12, 2018), [Available at: https://www.nbcnews.com/better/health/realistic-screen-timesolutions-kids-their-parents-ncna850056]

Searching (2018), Director: Aneesh Chaganty. Writers: Aneesh Chaganty and Sev Ohanian. Distributed by Sony Pictures Releasing, Jan. 21, 2018.

Smith, Adam and Edwin Cannan (2003), The wealth of nations. New York, N.Y: Bantam Classic.

The Nielsen Total Audience Report: Q1 2018, (accessed December 12, 2018), [available https://www.nielsen.com/us/en/insights/reports/2018/q1-2018-totalaudience-report.html]

YouTube, Apple and Facebook Ban Infowars, Which Decries 'Mega Purge', NPR, August 6, 2018 (accessed December 12, 2018), [available at https://www.npr.org/2018/08/06/636030043/youtube-apple-andfacebook-ban-infowars-which-decries-mega-purge] 